\title{
Application of Access Management Techniques to Large Shopping Mall in Beijing
}

\author{
Baiming Ding, Xiaokuan Yang \\ College of Metropolitan Transportation, Beijing University of Technology, Beijing, China \\ Email: dingbaiming@emails.bjut.edu.cn, xiaokuan@bjut.edu.cn
}

How to cite this paper: Ding, B.M. and Yang, X.K. (2016) Application of Access Management Techniques to Large Shopping Mall in Beijing. World Journal of Engineering and Technology, 4, 30-39. http://dx.doi.org/10.4236/wjet.2016.43C005

Received: May 3, 2016

Accepted: September 19, 2016

Published: September 22, 2016

\begin{abstract}
Conflicts are common phenomena in the field of traffic engineering, while are also the main cause of all the traffic problems. The vehicle access driveway of large shopping mall is often the conflict area of urban roads, traffic engineers and city managers face a great challenge as to make the traffic enter and exit the shopping mall safely and orderly. This paper studies the issues of access management of large shopping mall with a focus on Carrefour shopping mall in Shuangjin district, Beijing. This shopping mall attracts and generates lots of traffic during peak hours, those huge numbers of vehicles come in and out of the shopping mall through the access driveway, resulting in a lot of conflicts to the urban road traffic flow and deteriorating highly smooth movement of traffic on the urban roadway. The impacts of the existing design and layout of access driveway on surrounding traffic operation are also studied in this paper. Some countermeasure of improvements had proposed to decrease traffic conflicts and make sure that the traffic conditions get better off, all the improvement countermeasures are based on the access management principles. Results from this study can be a good reference on other similar driveways at large shopping mall areas.
\end{abstract}

\section{Keywords}

Large Shopping Mall, Traffic Conflicts, Driveway, Access Management

\section{Introduction}

With the development of society and economy, the country's household income increasing, citizens' consuming and shopping behavior is becoming more common either. Beijing as the capital of China, its social and economy development level is at the leading position among all the cities in China. It can be seen that on weekdays and weekends more and more people trend to go to the supermarket like Carrefour for 
shopping and entertainment, and high percent of those goers drives their car.

The vehicle access driveway is the gateway for car to come in and out of the shopping mall area. However, there is lack of standard and specification to dictate the lay-out and design for vehicle access in shopping area in China. As a result, conflicts and congestion can be seen in the driveways around the large shopping mall in Beijing. In order to decrease the conflicts and make the urban traffic flow smooth and safety under the existing traffic conditions, the proper way is to carry out the access management strategies. Access management has been defined as "the systematic control of the location, spacing, design, and operation of drive-ways, median openings, interchanges, and street connections to a roadway", as well as the application of median treatments, auxiliary lanes, and the appropriate spacing of traffic signals [1]. Previous studies showed that effective access management can be reduced accident rate by $50 \%$ than poor access management, and improve the traffic capacity from $23 \%$ to $45 \%$, therefore the travel time and delay can be reduced between $40 \%$ and $60 \%$ [1].

The US has applied access management techniques for many years in this respect, moreover, the importance of access management has been proved. Although the access management technology has made great development in the US, but we cannot directly apply it in China, because our city is different with America, the traffic situation in China is complicated. We need to find measures suitable for our own actual situation, meanwhile, we can still draw lessons from American experience and results. The objective of this study is to figure out problems through field observation and use access management techniques to find out improvements approach for the particular location.

In Beijing, there are many large shopping malls spreading over the city. This study takes Shuangjin Carrefour for example, a large shopping mall at the side of Guangqu Road in Chaoyang District as shown in Figure 1. The Shuangjin Carrefour is located between the East 3th Ring road and East 4th Ring road, adjacent to the Beijing Central Business District (CBD). It can be seen that there are many residential areas layout at

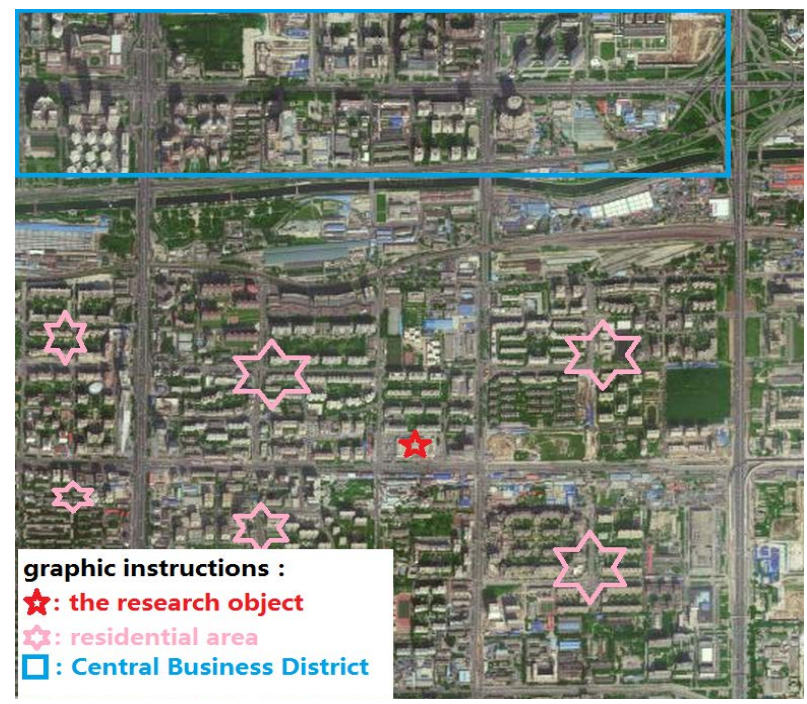

Figure 1. Project location. 
this district. Therefore, this location district has many people working and living here because the transportation is very convenient for them.

Shuangjin Carrefour shopping mall attracts and generates high volumes of traffic everyday especially on weekends. Meanwhile, it can be found that most driveways at this area are too improper to control the traffic movements, resulting in the mess-up of the traffic at this location and heavy congestion to the urban road around. The primary emphasis of this study is to testify and show the application of access management techniques, such as limiting the number of conflict points and separating conflict areas, those may mitigate the complex traffic situation and ensure safety. Therefore, some necessary data were collected at access driveways of the Carrefour shopping mall, including traffic volume of each driveway and adjacent roadways in peak hours, as well as the location, type and spacing of the access driveways. According to the analysis, some improvements were proposed for Shuangjin Carrefour shopping mall area to ensure traffic safety and maintaining the smooth flow of traffic based on access management principles.

\section{Literature Review}

Access driveway is a connection bridge between the buildings and urban roadways. The impact of driveway to urban roads varies with the location and type of access. Access driveway area is the key location where the origin of traffic jams produced. It is recognized that optimizing the access driveway is an effective approach to improve the urban traffic situation. A review of the literature reveals that many research projects have been conducted at home and abroad analyzed and showed the improvement effects of access management techniques.

The development of access management began in the 1970s by the United States Department of Transportation Federal Highway Administration. One of the primary focus areas for access management research has been on the physical characteristics of a roadway and the safety of the access driveway [2]. Some researches focus on the location principles and modes of vehicle access of large public buildings [3] [4]. In order to make access management achieve the expected purpose, the TRB Access Management Manual puts forward some principles of access management including: 1) Provide a specialized roadway system; 2) Limit direct access to major roadways; 3) Limit the number of conflict points; 4) Separate conflict areas; 5) Remove turning vehicles from through traffic lanes [1].

The Minnesota Department of Transportation commissioned a statewide study of the safety effects of access management. The results indicated that roadway segments with the highest access density have crash rates higher than average, regardless of type of access, speed limit, or volume of traffic. The study revealed a direct and statistically significant correlation between crash rates and access density for all state highway categories-urban and rural [3].

Gluck presented results of specially conducted operations analyses at 22 sites to study the effect of access spacing on traffic operations. Information was gathered on the 
number and percentage of through vehicles impacted by right turns. Access separation distances for various operating speeds and right-turn volumes were based on the likelihood of minimizing spillback across an upstream driveway over a series of driveways along a 1.4-mile section of road [4].

Some researches show that higher levels of access management projects have little or no negative impact on business events. Merchants often complain about access management, but the actual impacts appear rather benign. It means that stakeholder education is an important component of a comprehensive access management program [5].

The access of large public buildings, which has a strong distribution, plays an important role in urban traffic and seriously affects the smooth of the traffic flowing [6]. The traffic planning methods of large buildings access determine the construction and the operation mode. If the spacing between the two contiguous accesses is unreasonable, it is easily to lead to lack of enough buffer space. What's more, the urban road traffic will be disorder, and frequent accidents will be greatly generated [7].

It can draw the conclusion that these studies are mostly focused on the safety and operational impact of access design on surrounding traffic. Some methodologies and theories can be referenced to analysis of access driveways in Shuangjin Carrefour shopping mall area.

\section{Discussion and Results}

\subsection{The Status Quo}

Shuangjin Carrefour shopping mall is located at corner of Guangqu Road and Xidawang Road, that are the two arterials in Beijing roadway network. The investigation discovered there have five access driveways here for both vehicles, bicyclers and pedestrians at the shopping mall area, as shown in Figure 2. For vehicles, two driveways are single exit or entrance access and three driveways have any no limits, cars can exit and entrance at the same time. For pedestrians and bicyclers, all the five access driveways accept to them.

As shown in Figure 3, there have lots of messy traffic flows enter and exit the shopping mall through the five access driveways, which brings a lot of traffic conflicts to the surrounding urban roads. It can be seen the chaos in Figure 4. "Access- $A$ " is an entrance and exit driveway which attract vehicles from the arterial Guangqu Road. "Access-B" attract many traffic flows like "Access-A" too, the control type there is right-in and right-out. "Access- $C$ " is an entrance driveway at the intersection of the two urban roads, therefore this is the most chaos driveway in reality. "Access- $\mathrm{D}$ " is an exit driveway in the urban local road, which allows vehicle right-out and left-out. "Access-E" is similar to "Access-A", the control type here allows right-turn and left-turn too.

\subsection{Data Collection}

According to the characteristics of the study area, use video recorder and other necessary instruments to conducted investigations on weekdays and weekends. The data 


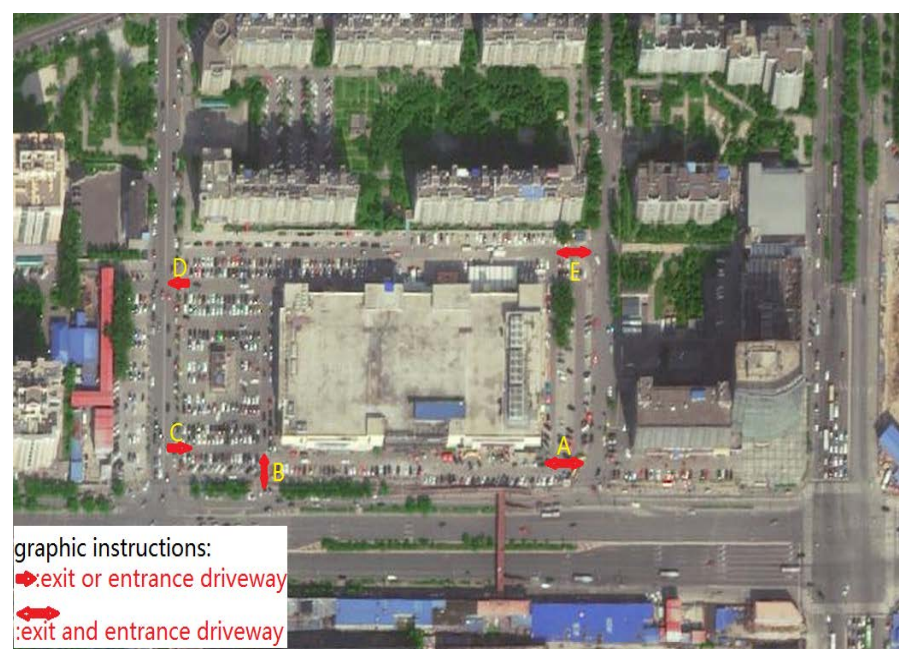

Figure 2. Location of access driveways.

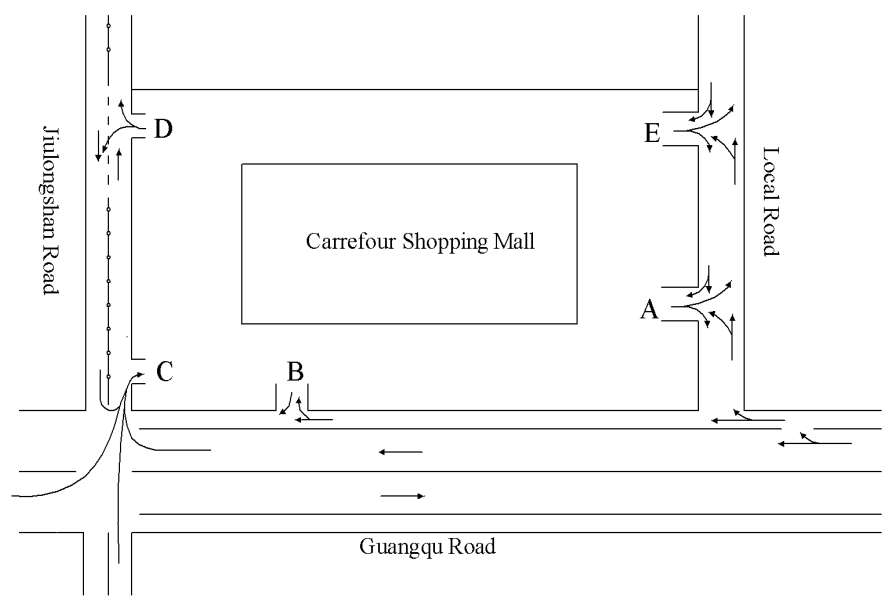

Figure 3. Vehicle flow directions.
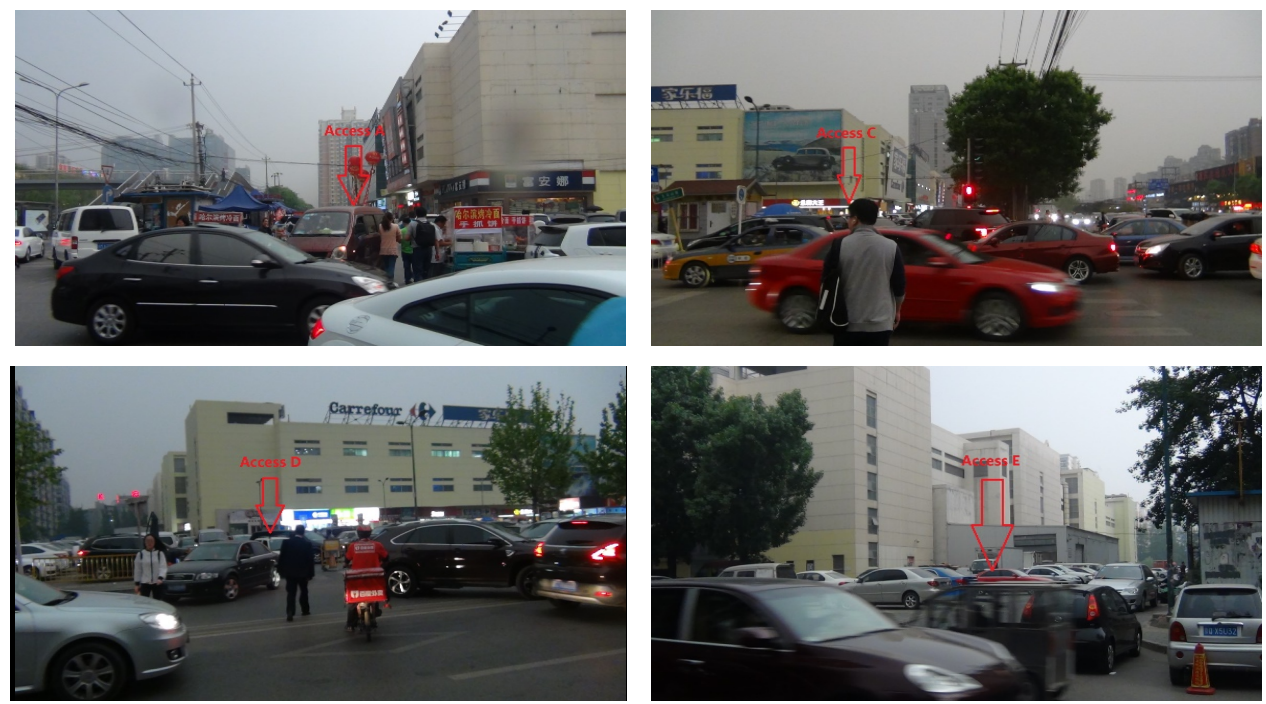

Figure 4. Conflicts at access driveways. 
were collected at all the five access driveways, including traffic volume of each access driveway and the adjacent roadways in peak hours, as well as the location, control type, spacing and any others of the driveway. Meanwhile, delays from interweaving of each driveway are included. The collected traffic data are shown in following Tables 1-3.

\subsection{Conflict Analysis}

The present situation and the collected data indicate that Guangqu Road is a very busy arterial road, too many cars flowing in and out of Carrefour shopping mall moment by moment from it. The traffic volume in Jiulongshan Road is moderate, and the volume in local Road, eastern side of Carrefour, is low in normal times. Next, we take "Access-A" for example, the traffic control type of this driveway is "left-turn permitted", which left-turn enter and exit allowed at the same time. Therefore, this organization mode leads to many conflicts, such as conflicts between left-turn vehicles from the

Table 1. Traffic volume of surrounding road in a peak hour.

\begin{tabular}{cccc}
\hline Item & Car (vehicle/hour) & Bus (vehicle/hour) & Total (vehicle/hour) \\
\hline Guangqu Road & 2240 (eastbound) & 300 (eastbound) & 4640 \\
& 1855 (westbound) & 245 (westbound) & 2079 \\
Jiulongshan Road & 1175 (southbound) & 25 (southbound) & \\
& 862 (northbound) & 17 (northbound) & \\
Urban local Road & 578 (southbound) & 0 (southbound) & \\
& 325 (northbound) & 3 (northbound) & \\
\hline
\end{tabular}

Table 2. Traffic volume of access driveways and conflicts number between surrounding road in a peak hour $(\mathrm{v} / \mathrm{h})$.

\begin{tabular}{cccccc}
\hline Name & Right-in & Right-out & Left-in & Left-out & Conflicts \\
\hline Access-A & 62 & 67 & 132 & 45 & 235 \\
Access-B & 167 & 45 & $/$ & $/$ & 52 \\
Access-C & 321 & $/$ & $/$ & $/$ & 289 \\
Access-D & $/$ & 211 & $/$ & 322 & 432 \\
Access-E & 54 & 122 & 165 & 45 & 312 \\
\hline
\end{tabular}

Table 3. Delays of each access driveways in a peak hour.

\begin{tabular}{cccccc}
\hline Item & Access-A & Access-B & Access-C & Access-D & Access-E \\
\hline Right-turn(s) & 176.2 & 76.6 & 547.6 & 87 & 45.3 \\
Left-turn(s) & 266.7 & $/$ & $/$ & 345.9 & 87.7 \\
Total(s) & 442.9 & 76.6 & 547.6 & 432.9 & 133 \\
\hline
\end{tabular}


shopping mall and vehicle driving straight on the urban local road. Moreover, there are no traffic signs to indicate the potential risk. The traffic conflict points are all marked in Figure 5. The other four access driveways' conflicts are present in Table 4.

All those conflicts only considered the vehicles between vehicles, the vehicles between bicycles and pedestrians are not taken into account, but in fact the status at those driveways are much more complex.

\subsection{Measures for Improvements}

The traffic conflict is the source of all the traffic problems, solve and ease the problem of access driveway also needs to consider how to reduce the traffic conflict's area. The paper put the following measures to improve those practical situations based on the access management techniques.

- Increase channelizing islands

The design of the proper channelizing islands can ensure vehicles move in order, as well as reducing conflicts. Through the investigate data upon, the "Access- $A$ " and "Access-E" at the eastern Carrefour can be applied, Let's take Access A for example. It's present in Figure 6.

- Provide adequate auxiliary lane

This provides enough space for queuing vehicles entering and exit the access driveway and reduces the potential conflicts. We take "Access-B" for example, adequate auxiliary road can let the entrance and exit cars wait and accelerate in it so that give a small impact to urban traffic. It shows in Figure 7.

Table 4. Conflicts in access driveways.

\begin{tabular}{cccccc}
\hline Item & Access-A & Access-B & Access-C & Access-D & Access-E \\
\hline Separation point & 3 & 1 & 4 & 1 & 3 \\
Conflict point & 3 & 0 & 5 & 1 & 3 \\
Conflux point & 3 & 1 & 14 & 4 & 3 \\
Total & 9 & 2 & & 2 & 9 \\
\hline
\end{tabular}

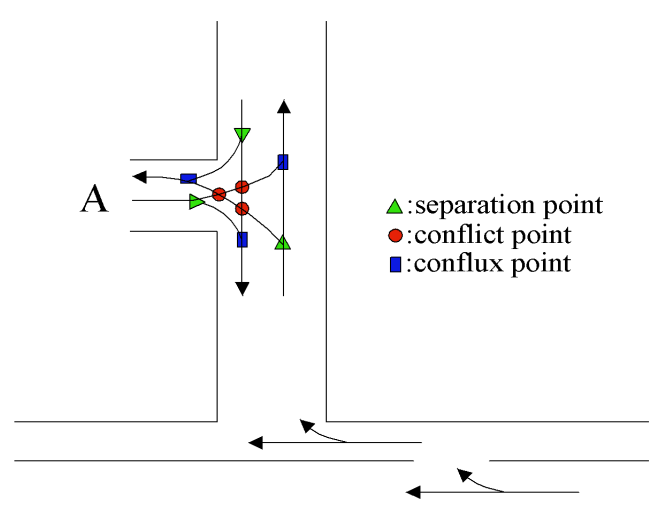

Figure 5. Conflicts at Left-turn permitted access. 


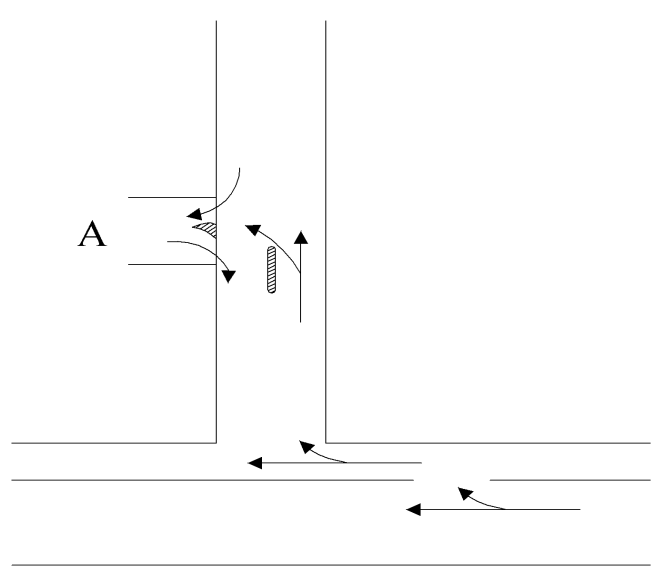

Figure 6. Channelizing islands.

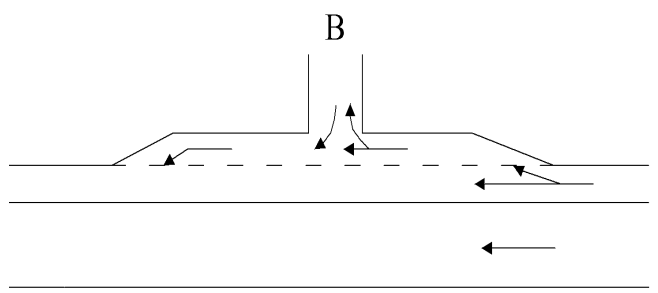

Figure 7. Auxiliary lanes.

- Increase the spacing between driveway and intersection

Spacing between access driveway and intersection is too short will disorder the intersection's traffic, the situation presented in Figure 4 upon. In this paper, it can move the "Access-C" far from the intersection, shows in Figure 8, because surrounded the Carrefour is a big parking space, this provides improvement conditions.

- Built physical median isolation

In order to reduce conflicts, it is necessary to use physical median isolation to restrict vehicles left-in and left-out of the access driveways at the chaos road, After the improvement, the left-turn traffic will make a U-turn route for enter and exit. This improvement can implement in Jiulongshan Road near the “Access-D” area. It's present in Figure 9 on the left side.

- Provide necessary traffic signs

Sufficient signs are provided to guide the drivers to aware that they can or can't enter or exit the shopping mall from the access driveways, including whether they can left-turn through the driveway ahead. For exit car from the mall, a STOP sign at the driveway can let driver to give way to urban traffic. Meanwhile, reasonable traffic signs can use to warn bicyclers and pedestrians to pay attention to ensure safety. It can reduce some potential risk.

- Separation of bicycler, pedestrians and motor vehicles access

Bicycler and pedestrians' trajectory often uncertainty, these are usually the key factors interfere with the access traffic. In this paper we can implement the bicyclers, pedestrians use different entrances and exits access driveway with vehicles. 


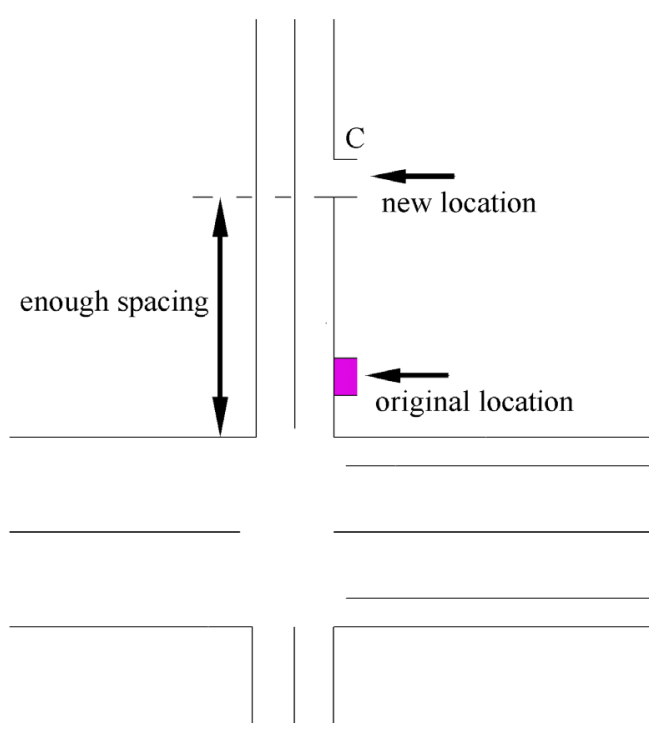

Figure 8. Increase enough spacing.

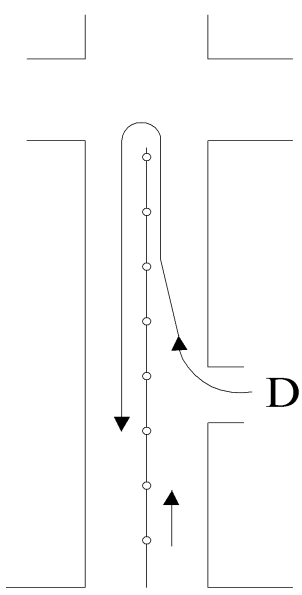

Figure 9. Make a U-turn rote.

\subsection{Simulation Evaluation}

After the relevant improvement measures to the access driveways, we use VISSIM simulation to predict the results. Simulation results are shown in Table 5.

From the table, it can be seen that the delays are decreased apparently, the decrement is about $11.4 \%$ average. It proved that the improve measures are effective to driveways of the Carrefour shopping mall in some extent.

\section{Conclusions}

First, the paper investigates and describes the current access situation in the area of Shuangjin Carrefour shopping mall in Beijing. The investigation indicates that the congestion and safety problems exist here, especially on weekends. Second, analyzing the access driveways' problem according to the actual exist situation, it had found there had many unscientific designs and traffic organization at the five driveways here. Third, 
Table 5. Delays before and after improvements.

\begin{tabular}{cccccc}
\hline Item & Access-A & Access-B & Access-C & Access-D & Access-E \\
\hline Before(s) & 442.9 & 76.6 & 547.6 & 432.9 & 133 \\
After(s) & 398.1 & 65.4 & 503.7 & 389.6 & 114.3 \\
Decrement & $10 \%$ & $15 \%$ & $8 \%$ & $10 \%$ & $14 \%$ \\
\hline
\end{tabular}

according to application experience of access management technologies at home and aboard, some countermeasures of improvements were proposed to decrease traffic conflicts and ensure a smooth and efficient road network, such as add channelizing islands and auxiliary lanes, increase the spacing between driveway and intersection, build physical median isolation, provide necessary traffic signs, separation of bicycler, pedestrians and motor vehicles access, and so on. Finally, use VISSIM to simulation the improvements' results, and the results shows that the delays decreased after improved.

The study can be a good reference for traffic engineers and city managements on other similar driveways at large shopping mall areas in a certain extent.

\section{References}

[1] Committee on Access Management, Access Management Manual, Transportation Research Board, Washington DC, 2003.

[2] Schultz, G.G., Braley, K.T. and Boschert. T. (2008) The Relationship between Access Management and Other Physical Roadway Characteristics and Safety. Journal of Transportation Engineering, 136, 141-148.

[3] Preston, H., Newton, R., Albrecht, C. and Keltner, D. (1998) Statistical Relationship between Vehicular Crashes and Highway Access. Report MN/RC-1998-27. Local Road Research Board, Minnesota Department of Transportation, August 1998.

[4] Gluck, J.S., Haas, G., Mahmood, J. and Levinson, H.S. (2000) Driveway Spacing and Traffic Operations. TRB Circular E-C019: Urban Street Symposium. Transportation Research Board, Washington DC.

[5] Maze, T. and Plazak, D. (1997) Access Management Awareness Program: Phase II Report. Iowa Highway Research Board Project TR-402. Center for Transportation Research and Education, Iowa State University, Ames, Iowa.

[6] Chen, J. and Wang, W. (2004) Traffic Organization Analysis on Entrance and Exit of Off-Road Parking Lot. Journal of Southeast University (Natural Science Edition), No. 34, 100-103 (in Chinese).

[7] Zhuo, X., Qian, Z.D. and Zhang, N. (2012) Spacing Calculation for Same-Side Vehicle Access of Large Public Building. Journal of Southeast University (Natural Science Edition), No. 42, 560-564 (in Chinese). 
Submit or recommend next manuscript to SCIRP and we will provide best service for you:

Accepting pre-submission inquiries through Email, Facebook, LinkedIn, Twitter, etc. A wide selection of journals (inclusive of 9 subjects, more than 200 journals)

Providing 24-hour high-quality service

User-friendly online submission system

Fair and swift peer-review system

Efficient typesetting and proofreading procedure

Display of the result of downloads and visits, as well as the number of cited articles

Maximum dissemination of your research work

Submit your manuscript at: http://papersubmission.scirp.org/

Orcontactwjet@scirp.org 